\title{
A PARTICIPAÇÃO DAS ONGS NA ORGANIZAÇÃO MUNDIAL DO COMÉRCIO'
}

Felipe Machado ${ }^{2}$

\section{INTRODUÇÃO}

Tradicionalmente, as relações internacionais têm sido caracterizadas pela presença de um único ator legítimo: os Estados soberanos. Os Estados sozinhos têm negociado acordos multilaterais, aceitado compromissos e reforçado suas próprias obrigações internacionais. São os Estados os responsáveis por essa nova dinâmica mundial que chamamos de globalização. No entanto, esse mesmo processo gerado pela interação cada vez maior entre os Estados permitiu a criação de setores da sociedade que contestam o conceito tradicional do direito internacional, qual seja, o direito das nações ${ }^{3}$. Dentre os grupos não-estatais ${ }^{4}$ mais ativos, podemos encontrar as Organizações Não Governamentais $\left(\mathrm{ONGs}^{5}\right)$.

Nesse contexto, onde os Estados praticam intensas rodadas multilaterais de negociação, surge, em 1994, na Rodada do Uruguai, a Organização Mundial do Comércio. A organização visa total liberalização do comércio mundial, administrando os fluxos de comércio, estabelecendo as ligações e o comportamento das transações comerciais internacionais, respeitando as fronteiras dos Estados, e protegendo o sistema econômico

\footnotetext{
1 Trabalho apresentado na disciplina de Direito Internacional Econômico: Comércio Internacional, da Faculdade de Direito da Universidade Federal do Rio Grande do Sul, ministrada pelo Prof. Dr. Fábio Morosini.

${ }^{2}$ Felipe Machado é graduando do quinto semestre do curso de Relações Internacionais da UFRGS e bolsista de Iniciação Científica PIBIQ/CNPq do Núcleo de Estratégia e Relações Internacionais (NERINT-UFRGS).

${ }^{3}$ BROWLIE, Ian. Princípios de Direito Internacional Público. Lisboa: Oxford University Press, 1997, p.73.

${ }^{4} \mathrm{O}$ presente artigo trabalha com o conceito de ator não estatal para qualificar as ONGs, não sendo este conceito utilizado em momento algum do texto para tratar de associações parlamentares, governos subnacionais, empresas e indivíduos.

${ }^{5}$ Neste artigo, entende-se por Organização Não Governamental (ONG) todo e qualquer conjunto de atores os quais a OMC prevê algum tipo de tratamento especial, especificando, a necessidade de este apresentar um caráter de instituição sem fins lucrativos. Para provar que não é um ator que visa o lucro, uma ONG precisa produzir um documento de registro ou uma carta apontando o propósito da organização. Se isto não está disponível, a OMC requisita no mínimo a produção de documentos que provem que a organização formalmente existe.
}

Revista Brasileira de Direito Internacional, Curitiba, v.7, n.7, jan./jun.2008 
global das chamadas falhas de mercado ${ }^{6}$. Apesar de seu caráter intergovernamental, a OMC tem se defrontado cada vez mais com a pressão de atores não-estatais, que objetivam alcançar uma participação maior nas atividades desenvolvidas dentro dessa instituição.

Dessa forma, o presente artigo pretende analisar a participação das ONGs dentro da Organização Mundial do Comércio. A inquietação intelectual que leva a criação de tal trabalho é advinda do fato de se tentar comprovar que as ONGs não devem participar mais efetivamente dos debates sobre a liberalização do comércio mundial. O objetivo, assim, é corroborar com a corrente de autores que acreditam que as ONGs não deveriam participar mais ativamente dos debates a cerca das relações comerciais internacionais.

\section{MODELOS DE GOVERNANÇA DA OMC}

Os recentes esforços desenvolvidos pelas ONGs com o intuito de participar da política de negócios internacionais, ajudando nas deliberações sobre o assunto, encontraram certo grau de hostilidade por parte da comunidade internacional. Com o objetivo de encontrar um marco teórico que caracterizasse os modelos de gerência da organização e que, ao mesmo tempo, visualizasse a participação mais efetiva das ONGs, Robert Shell trabalhou no desenvolvimento de três modelos de governança para explicar o funcionamento da Organização Mundial do Comércio: o modelo que analisa a conduta dos regimes, o modelo de eficácia do mercado e o modelo trade stakeholders ${ }^{7}$.

O modelo que analisa a conduta dos regimes é o que melhor descreve, segundo o autor, a atual estrutura de dominação dos Estados na OMC. Este modelo deriva da chamada teoria dos regimes desenvolvida pela literatura de organizações internacionais no campo da ciência política. Para Shell, a teoria

\footnotetext{
${ }^{6}$ Segundo Mankiw, essa seria uma situação na qual o Mercado falha em alocar eficientemente seus recursos escassos. MANKIW, Gregory. Principles of Macroeconomics. São Paulo: IE WW Norton, 2006, p.11.

7 SHELL, R. Participation of nongovernmental parties in the World Trade Organization: the Trade Stakeholders Model and the participation $\mathrm{b}$ non-state parties in the World Trade Organization. Journal of International Economic Law, Vol. 17, 1996, p.359-371.
}

Revista Brasileira de Direito Internacional, Curitiba, v.7, n.7, jan./jun.2008 
dos regimes nada mais é do que uma ramificação da tradicional corrente realista de teoria das relações internacionais, a qual foca no fato de os Estados soberanos serem os atores principais do sistema internacional, e aceita estes como sendo a única voz para representar as suas populações internacionalmente. Visto como um regime formal de negociações, o sistema legal da OMC tem a intenção de prover aos Estados um conjunto consistente de regras internacionais. Estas regras pretendem induzir os Estados a negociar as relações comerciais na sombra do direito internacional, disposição esta, melhor do que a tradicional base das relações de poder.

O modelo de eficiência dos mercados deriva da combinação da teoria liberal de relações internacionais e do comprometimento ideológico com a doutrina neoclássica de liberalização do comércio mundial. Sob os auspícios do liberalismo, os Estados não são nem concebidos atores autônomos e maximizadores de interesses, nem como os únicos atores internacionais. Já o modelo do trade stakeholders apresenta-se como uma visão alternativa sobre as relações entre o comércio e as políticas sociais, e os indivíduos e grupos não-estatais como atores fundamentais das relações internacionais.

Por fim, o trabalho encara como melhor modelo de governança para o regime de comércio mundial aquele que, segundo Shell, vigora atualmente dentro da OMC, qual seja, o modelo da conduta dos regimes.

\section{A PARTICIPAÇÃO DAS ONGS NA OMC}

Uma primeira disposição sobre a participação direta das ONGs na OMC consta do Artigo V.2 do Acordo de Marrakesh, acordo este, que estabeleceu a OMC. Este artigo dispõe que o Conselho Geral da OMC poderá tomar as providências necessárias para manter consultas e cooperar com as ONGs dedicadas a assuntos relacionados aos da $\mathrm{OMC}^{8}$. Além disso, as Diretrizes para o arranjo das relações da OMC com as Organizações Não Governamentais, adotadas por decisão do Conselho Geral em 18 de Julho de

\footnotetext{
${ }^{8}$ SANCHEZ, Michelle Ratton. Breves observações sobre os mecanismos para participação das ONGs na OMC. Sur Revista Internacional de Direitos Humanos. Vol.1, No. 4, 2006, p.105
}

Revista Brasileira de Direito Internacional, Curitiba, v.7, n.7, jan./jun.2008 
1996, estipulam que deve partir do Secretariado as iniciativas para uma maior participação, se de interesse da organização, das $\mathrm{ONGs}^{9}$.

Em geral, classificam-se as formas de participação em fóruns intergovernamentais em quatro categorias: (i) informação; (ii) consulta; (iii) cooperação; e (iv) deliberação ${ }^{10}$. No acordo Constitutivo da OMC, estão expressamente discriminadas as formas (ii) e (iii). Quanto à informação, o princípio da transparência deve ser considerado como fundamental para a organização. Como a OMC é uma instituição intergovernamental, a deliberação em si fica restrita aos Governos dos Estados-membros. Neste caso, as Diretrizes deixam claros os limites para o envolvimento das ONGs. No parágrafo de conclusão, o Conselho Geral refere-se categoricamente a este caráter da OMC. Como resultado desses debates, há uma clara e ampla visão de que não seria possível para uma ONG estar diretamente envolvida nos trabalhos da Organização Mundial do Comércio ou de suas reuniões. A este, o Conselho Geral acrescentou:

\footnotetext{
"Consultas chave e cooperações com as ONGs podem também se apresentar construtivamente através de processos apropriados desenvolvidos em âmbito nacional onde jaz a responsabilidade primária por tomar qualquer iniciativa frente a diferentes elementos do interesse público que são trazidos para os debates da formação de leis sobre o comércio ${ }^{11}$ ".
}

As participações das ONGs até o momento na OMC são definidas nos seguintes parâmetros: participação em Conferências Ministeriais, envolvimento em simpósios e fóruns, por iniciativas do Secretariado, reuniões informais e pelas trocas de informações.

\footnotetext{
${ }^{9}$ LIN, Zhengling. An Analysis of the Role of NGOs in the WTO. Chinese Journal of International Law, Vol.3, 2004, p.488

${ }_{11}^{10}$ SANCHEZ, M. Breves, acima 6, p.105

11 "Guidelines for arrangements on relations to Non-Governmental Organizations". Decision adopted by the General Council on 18 July 1996. http://www.wto.org/english/forums_e/ngo_e/guide_e.htm (acesso em 15 de Junho de 2009).
}

Revista Brasileira de Direito Internacional, Curitiba, v.7, n.7, jan./jun.2008 


\subsection{CONFERÊNCIAS MINISTERIAIS}

Enquanto as Diretrizes de 1996 não elucidam qualquer perspectiva de participação das ONGs nas Conferências Ministeriais, por uma decisão do Conselho Geral na primeira Sessão da Conferência Ministerial realizada em Cingapura em 1996, as ONGs foram convidadas para comparecer as reuniões do plenário da conferência. Esta foi a primeira participação das ONGs em conferências ministeriais, contudo, vale ressaltar, que seu status não foi nem de observador, tampouco foi lhes permitido qualquer tipo de pronunciamento.

A participação das ONGs em Conferências Ministeriais, desde então, tem sido cada vez maior. Nesta primeira, das 159 ONGs inscritas 108 compareceram, chegando-se ao número de 856 em Hong Kong, $2005^{12}$.

\subsection{SIMPÓSIOS E FÓRUNS}

A realização de simpósios e fóruns que permitem entre a $\mathrm{OMC}$ e as ONGs, diferentemente das Conferências Ministeriais, estão previstas nas Diretrizes das relações da organização com as ONGS de 1996. Este formato é criticado pela ineficácia, pois as discussões são pouco focadas e geram conclusões muito gerais ${ }^{13}$. Em reação a este criticismo, em 2000, a OMC mudou o formato dos simpósios e mudou sua periodicidade, sendo estes realizados então anualmente em eventos de dois a três dias, concomitante a diversos workshops e seminários nos quais os panelistas e os participantes interessados discutem uma gama de assuntos relacionados às questões tratadas pela OMC. Estes simpósios são financiados com recursos extraorçamentários, em particular, com contribuições voluntárias de membros da OMC.

O papel da OMC na organização nos simpósios é confinado a assuntos, como o arranjo das salas, explicação e apoio financeiro aos

\footnotetext{
12 VAN DEN BOSSCHE, Peter, NGO Involvement in the WTO: A Comparative Perspective. Journal of International Economic Law, Vol. 11, No. 4, 2008, p. 726-27.

${ }^{13}$ CHARNOVITZ, S. Opening the WTO to Non-governmental Interests. Fordham International Law Journal, Vol. 24, 2000, p.191.
}

Revista Brasileira de Direito Internacional, Curitiba, v.7, n.7, jan.jun.2008 
panelistas de países em desenvolvimento. Os temas dos seminários, bem como os panelistas, são selecionados pelas ONGs, tornando a função da OMC meramente organizacional.

\subsection{ACESSO AS INFORMAÇÕES DA OMC}

Um dos pontos mais frágeis e contestados pelas ONGs está relacionado à transparência da OMC. As ONGs alegam que o organismo demorava a liberar os documentos produzidos e que era seletivo ao divulgálos. Com o objetivo de preencher essa lacuna, a Organização Mundial do Comércio lançou seu site em 1995, e este rapidamente se tornou uma valiosa ferramenta para as ONGs tomarem conhecimento do que ocorre dentro dos processos da organização. Os aspectos mais ressaltos da eficácia do site da OMC é a disponibilidade de textos completos de documentos nas três línguas oficiais da organização (Inglês, Francês e Espanhol), rápido acesso as novas decisões tomadas pelos painéis da OMC e pelo Órgão de solução de controvérsias, textos dos acordos da OMC e a grade de horários das vindouras reuniões da organização.

O acesso a informações e contatos da ONGs ficou ainda mais fácil depois que poucas semanas antes da Conferência Ministerial de Seatle (1999), o Secretariado criou uma página na web ${ }^{14}$ para responder diretamente às críticas à OMC. Esta seção explica também que as ONGs não podem participar diretamente da OMC, e que podem somente exercer sua influência sobre as decisões da OMC através de seus governos nacionais. Este explicação torna evidente que, ao permitir as ONGs o acesso especial à OMC minaria os benefícios advindos da construção de um regime internacional do comércio mecanismo que reduzem o poder de grupos de interesse posto que permite o comércio e a democracia florescerem das deliberações dessa instituição ${ }^{15}$.

Ainda na observância das diretrizes de 1996, algumas outras possibilidades de trocas de informações entre as ONGs e a OMC podem ser

\footnotetext{
${ }^{14}$ Ver WTO, 'For NGOs', http://www.wto.org/english/forums_e/ngo_e.htm (acesso em 15 de julho de 2009).

${ }^{15}$ Ver LIN, Z. An Analysis, acima 7, p. 491
}

Revista Brasileira de Direito Internacional, Curitiba, v.7, n.7, jan./jun.2008 
visualizadas, entre elas podemos citar a realização de reuniões informais entre os presidentes de conselhos ou comitês da OMC e as ONGs. Não há, no entanto, procedimentos claros que governam tal iniciativa. Elas tomam corpo através de interesses manifestos tanto das ONGs como de algum presidente de conselho ou comitê. Nessas reuniões há, geralmente, a troca de informações e pontos de vista, a maioria no tocante das negociações correntes. O Secretariado também tem a prerrogativa de participar reuniões informais com as ONGs. Estas reuniões são organizadas sob uma base ad hoc onde trâmites das negociações e questões técnicas podem ser tratadas, entretanto, sem uma periodicidade concreta. A ocorrência dessa interação OMC-ONGs, por outro lado, é quase que semanal ${ }^{16}$.

Adicionalmente, três ou quatro vezes ao ano, o Secretariado organiza apresentações de estudos ou publicações das ONGs. Estas apresentações são realizadas para o benefício dos delegados dos Estados-membros. Contudo, devido à agenda cheia desses delegados ou outros fatores, estas apresentações têm contado com um número pequeno de interessados. $O$ Secretariado, durante e ao fim de reuniões importantes, emite comunicados à imprensa para manter a todos informados sobre o processo de evolução das negociações. Por fim, existe a possibilidade de aceitação pelo Secretariado de posições por escrito feitas pelas ONGs, sem qualquer obrigação jurídica de aplicá-las, nem mesmo de sugeri-las num debate com os demais membros da organização.

\section{OS ANSEIOS POR UMA PARTICIPAÇÃO MAIOR}

A participação da ONGs, apesar de limitada pelo próprio status de adesão de membros da organização, ainda resulta numa briga por mais espaço. As previsões para a participação direta das ONGs na OMC constam, segundo Michelle Sanchez, de seu Acordo Constitutivo, de documentos e de decisões adotados no funcionamento da organização, pelos Membros ou pelo Secretariado. De acordo com as previsões de participação e das demandas

${ }^{16}$ VAN DEN BOSSCHE, P. NGO involvement, acima 11, p.734

Revista Brasileira de Direito Internacional, Curitiba, v.7, n.7, jan./jun.2008 
apresentadas para seu aprimoramento, as influências na regulamentação da OMC podem-se dar em três níveis: na criação de regras, nas rodadas de negociações e, na implementação e no processo de sua interpretação, com vistas a solucionar controvérsias.

\subsection{FUNÇÕES LEGISLATIVAS}

Como os debates a cerca das relações comerciais internacionais têm ganhado saliência nos últimos anos, muitas ONGs passaram a desenvolver interesses em participar da formulação de políticas na OMC. Definir os limites da participação da ONGs no desenvolvimento de políticas, revisão, e nas atividades de produção de regras requereria o desenvolvimento de uma estrutura mais complexa de criação de leis dentro da $\mathrm{OMC}^{17}$.

Como já visto acima, a participação das ONGs nas Conferências Ministeriais - uma das formas de criar políticas dentro da OMC - pode ser feita através de quatro principais atividades: (i) conhecimento do andamento das negociações promovido pelas notas à imprensa escritas pelo Secretariado após as reuniões; (ii) organização de pequenas mesas de debates; (iii) organização de grupos de trabalho; e, (iv) possibilidade de aceitação pelo Secretariado de posições por escrito ${ }^{18}$.

O processo de aplicação das regras, por outro lado, não apresenta nenhum envolvimento das ONGs. Na estrutura institucional da OMC, os principais mecanismos para aplicação das regras são o trabalho periódico do Mecanismo de Revisão de Políticas Comerciais e o trabalho cotidiano dos Conselhos e Comitês da OMC. No entanto, para nenhum desses órgãos envolvidos na aplicação das regras há a previsão de participação de ONGs nos documentos oficiais da organização.

\subsection{NEGOCIAÇÕES COMERCIAIS}

17 ESTY, Daniel. Non-Governmental Organizations at the World Trade Organization: Cooperation, Competition, or Exclusion. Journal of International Economic Law, Vol. 1, No. 1, 1998, p.145

${ }^{18}$ SANCHEZ, M. Breves, acima 6, p.110

Revista Brasileira de Direito Internacional, Curitiba, v.7, n.7, jan./jun.2008 
Atualmente, as negociações comerciais permanecem fundamentalmente caracterizadas pelo processo direto de barganha entre governos e, assim, apresenta-se como o caso mais forte e difícil de contar com a participação das ONGs, tendo em vista o ambiente sigiloso que compõe as negociações. Dada a complexidade de promover acordos comerciais e o acréscimo advindo das dificuldades de se abrir o processo de negociação, um mandato da OMC que permitisse a participação das ONGs nas rodadas de negociação desnortearia, sem sombra de dúvidas, o caminho dos debates, além, é claro, de restringir a ação dos atores, pois estes poderiam não querer expor todos os seus mecanismo de negociação na presença de terceiros.

As negociações com as ONGs de um específico Estado poderiam também aumentar a força dos argumentos de tal Estado, da mesma maneira que poderia desestruturar as estratégias de negociação. Se as autoridades nacionais desejam compartilhar suas posições e estratégias de negociações com as ONGs, elas poderiam realizar isso em âmbito interno individualmente.

\subsection{O MECANISMO DE SOLUÇÃO DE CONTROVÉRSIAS}

O organismo de solução de controvérsias é, dentre todos os membros da OMC, considerado o mais importante e bem-sucedido mecanismo de resolução política das adversidades entre os Estados membros da organização. Ambos os países desenvolvidos e em desenvolvimento utilizamse constantemente desse sistema. Desde a formação deste tipo de procedimento dentro da $\mathrm{OMC}$, os debates têm sido fechados ao público. Consultas, painéis, procedimentos, e a revisão dos procedimentos de apelação são, em via de regra, confidenciais ${ }^{19}$. Os argumentos para o envolvimento das ONGs no mecanismo de solução de controvérsias ou no órgão de apelação são os mais diversos, contudo, esta seção trata de analisar somente os anseios e o atual nível de participação dessas entidades neste espaço da

\footnotetext{
${ }^{19}$ A disposição relativa à confidencialidade das reuniões dos painéis está contida no Working Procedures do painel localizados no Apêndice 3 da compreensão da OMC sobre regras e procedimentos para a solução de litígios.
}

Revista Brasileira de Direito Internacional, Curitiba, v.7, n.7, jan./jun.2008 
OMC. O pedido de participação nesses tipos de procedimento apresenta-se como fruto da incompreensão dos termos jurídicos que compõe os artigos constitutivos desse órgão. A limitada participação das ONGs no mecanismo de solução de controvérsias e nas reuniões dos painéis deve-se, então, ao caráter confidencial que este apresenta.

Atualmente, a participação das ONGs é permitida nas reuniões dos mecanismos de solução de conflitos como observadores. Este envolvimento das ONGs está baseado na figura do amicus curiae ${ }^{20}$. A aceitação de declarações de amicus curiae não solicitados pelos painéis e pelo órgão de apelação, e, em particular, aqueles que submetem 0 pedido independentemente das partes, tem sido muito controvertido e criticado pelos membros da OMC. Sua primeira ocorrência se deu no caso do Camarão - EUA. Dessa forma, elas podem assistir todos os procedimentos quando as partes apresentam as evidências nas disputas dos painéis e têm acesso as submissões escritas.

Por fim, podemos avaliar esse desejo de participar mais efetivamente tanto do processo 'legislativo' como do processo 'executivo' da OMC como contraditório. Ele, desde já, serve para apontar a inconformidade do envolvimento das ONGs dentro da OMC. A busca pela formalização é cheia de contradições. Por exemplo, argumentar que as ONGs deveriam ter um maior papel, mais formal na área 'executiva' e 'legislativa' dos assuntos da OMC, e, ao mesmo tempo, deveriam ter a permissão para participar dos procedimentos do mecanismo de solução de controvérsias porque eles carecem de algumas palavras do 'executivo' e do 'legislativo' é um tanto vago ${ }^{21}$, pois as ONGs, sem bem apontadas suas colaborações, não precisariam ajudar na solução de

\footnotetext{
${ }^{20}$ BLACK's Law Dictionary, 1990, p.82: "Amicus Curiae". Significa literalmente amigo da corte. Uma pessoa com forte interesse ou visões sobre o objeto de uma ação, mas que não faz parte da ação, pode fazer uma petição ao tribunal solicitando permissão para protocolar um relatório de forma ostensiva em nome de uma parte, mas, na verdade, sugerindo um raciocínio consistente com suas próprias visões. Ver VAN DEN BOSSCHE, P. NGO Involvement, acima 11, p.739. A figura do Amicus Curiae, segundo Bossche, pode servir para três diferentes funções: (i) prover análise legal e interpretação do caso; (ii) prover análise factual assim como evidências; e, (iii) posicionar as disputas comerciais num contexto político e social mais amplo.

${ }^{21}$ SLOTBOOM, M. Participation of NGOs before the WTO and EC tribunals: which court is the better friend? World Trade Review, Vol. 5 No. 1, 2006, p.100
}

Revista Brasileira de Direito Internacional, Curitiba, v.7, n.7, jan./jun.2008 
controvérsias, visto que sua colaboração na parte legislativa teria, por ora, ajudado a evitar o surgimento de controvérsias.

\section{POSICIONAMENTOS PRÓ E CONTRA AS ONGS NA OMC}

As recentes demandas das ONGs por uma formalização de sua participação no âmbito interno da OMC é acompanhado por um intenso debate acadêmico entre aqueles que defendem a participação das ONGs e aqueles que são contrários a formalização do envolvimento dessas entidades com os assuntos comerciais internacionais. A seguir os principais argumentos prós e contras essa participação.

\subsection{ARGUMENTOS A FAVOR DA PARTICIPAÇÃO DAS ONGS}

Os esforços das Organizações Não-Governamentais em participar das atividades de formulação de políticas dentro da OMC é motivo de aclamação por muitos acadêmicos e entusiastas de uma sociedade global onde a participação da sociedade civil organizada reduz as disparidades promovidas pelos Estados. As ONGs oferecem a OMC, segundo Daniel Esty, um mecanismo que facilita a interlocução entre os cidadãos ao redor do mundo, interessados na liberalização do comércio mundial e a organização, além, é claro, de se mostrar mais vantajoso e eficaz na disseminação dos ideais de um mundo sem barreiras ${ }^{22}$. Melhorar a responsividade e a representatividade por parte da OMC e melhor compreender o sistema de comércio internacional por parte da sociedade poderiam aumentar a legitimidade da organização e fortalecer sua posição como elemento central da emergente estrutura de governança econômica global. As ONGs oferecem, além disso, uma fonte analítica de 'competição' aos governos que promete fortificar a capacidade da OMC de regular de um jeito que evite as falhas de mercado e melhora as tomadas de decisão da organização amplamente, acrescentando mais adiante, a credibilidade e autoridade da OMC.

${ }^{22}$ ESTY, D. Non Governmental, acima 16, p.123

Revista Brasileira de Direito Internacional, Curitiba, v.7, n.7, jan./jun.2008 
A mágica dos mercados é agora extensamente apreciada por essas entidades. Mas, os mercados às vezes falham, e quando eles o fazem, intervenções governamentais são necessárias para evitar a distribuição ineficiente e as perdas de bem-estar. Contudo, segundo Lin, quando os governos nacionais tentam consertar as falhas de mercado internacionais, disputas tendem a emergir ${ }^{23}$. Como instituição chave com mandato para gerenciar os termos de troca do comércio internacional e para estabelecer a adoção de comportamentos para o comércio fronteiriço, a $O M C$ não pode escapar da sua responsabilidade, tampouco as ONGs. Tendo em vista as dificuldades que a OMC têm para cumprir seu papel, acredita-se que seu papel seria melhor desenvolvido se esta formalizasse a ajuda proveniente das ONGs nos assuntos do comércio internacional. Especificamente, as ONGs oferecem a promessa de servir como um 'tecido conetivo' que ajudará a preencher o vácuo entre os tomadores de decisão da OMC e os distantes componentes que eles supostamente representam, assegurando que as ações da OMC serão percebidas como responsáveis e justas. Abaixo são analisados alguns dos principais argumentos pró ONGs ${ }^{24}$.

Primeiro, os Estados são imperfeitos representantes da opinião pública. Enquanto os governos têm o monopólio legal sob o uso da força, eles não detêm o monopólio da criação de boas idéias para alcançar as metas estabelecidas no preâmbulo do acordo constitutivo da OMC, tal como aumentar o padrão de vida, assegurar o pleno emprego e eliminar o tratamento comercial internacional discriminatório. Os governos desrespeitam sistematicamente os pontos de vista das minorias. Permitindo que as ONGs participem das discussões na OMC poderia permitir a organização escutar vozes importantes que, em todo o caso, não seriam ouvidas e não estariam representadas.

Segundo, as ONGs podem servir como maximizadores das capacidades da OMC. Ministros do Comércio freqüentemente carecem de

\footnotetext{
${ }^{23}$ LIN, Z. An Analysis, acima 7, p.492.

${ }^{24}$ Para argumentos a favor da formalização da participação das ONGs dentro da OMC, ver ESTY, D. Non Governmental, acima 16, p.131-35; LIN, Z. An Analysis, acima 7, p.492-96; DUNOFF, J. The Misguided Debate Over NGO Participation at the WTO. Journal of International Economic Law, Vol. 1, No. 3, 1998, p. 435-436; CHARNOVITZ, S. Opening, acima 12, p191; e, VAN DEN BOSSCHE, P. NGO involvement, acima 11, p.720.
}

Revista Brasileira de Direito Internacional, Curitiba, v.7, n.7, jan.jun.2008 
recursos para investigar a fundo e desenvolver os casos sem aquiescência. Neste caso, as ONGs geralmente têm acesso a informações e contato com especialistas que os governos não têm. Dentro desta perspectiva, aponta-se para o compartilhamento dessas fontes entre as ONGs e a OMC, aumentando assim a qualidade das negociações e das resoluções de conflito. Além disso, mais informações e um maior número de argumentos também permitiriam a redução da probabilidade de emissão de pareceres errôneos.

Terceiro, as ONGs provêem uma supervisão adicional e mecanismos de auditoria. Bem informados grupos da sociedade podem agir como vigilantes dos governos nacionais e prestar atenção se eles estão cumprindo suas obrigações sob o regime do direito internacional econômico. Com melhor acesso a documentos e reuniões, as ONGs atuariam também como um ponto crítico e de revisão do desempenho da OMC. Além disso, as Organizações Não-Governamentais poderiam servir como meio de divulgação e compartilhamento de informações sobre o sistema internacional para a sociedade civil. Explicar o que está acontecendo dentro do regime de negociações comerciais e desenvolver a apreciação pública sobre a liberalização do comércio internacional em geral e sobre as decisões da OMC, em particular.

O quarto argumento se foca na percepção de falta de legitimidade da OMC. Preocupações sobre o déficit democrático da organização têm aumentado crescentemente ante os defensores das ONGs. Muitos têm sugerido que a natureza fechada das políticas da OMC e do processo de solução de controvérsias mina a confiança pública na integridade e na autoridade das decisões da instituição. A participação das ONGs aumentaria, dessa forma, a legitimidade da OMC, pois estas teriam a oportunidade de serem ouvidas e observar o processo de tomada de decisões. Elas também poderiam complementar essa falta de transparência disseminando, em nível nacional, a compreensão do sistema.

Um quinto argumento leva em conta a responsividade e a representatividade dos tomadores de decisão para moldar as impressões sobre a sua autoridade e confiabilidade no processo de tomada de decisões. Quando 
quer que as escolhas políticas derivem dos mais altos - mais centralizados níveis de governo, que são inescapavelmente mais distantes da cidadania local, questões de representatividade e o medo do déficit democrático deve emergir. O sistema de comércio internacional tem sido historicamente vulnerável nesse ponto, enfrentando ataques regulares por causa da percepção de que uma sigilosa conspiração 'sem cara' de burocratas internacionais em Genebra tomaria decisões sem completa apreciação dos impactos no nível local dos países pelo mundo. Outra alegação é de que as pessoas hoje em dia não têm uma identidade determinada pela geografia da jurisdição política na qual elas nasceram. Neste caso, as Organizações NãoGovernamentais, que cruzam diversas fronteiras políticas, poderiam definir e representar uma comunidade de interesses. Seria então, uma representatividade alternativa.

Finalmente, a crescente apreciação sobre a riqueza e diversidade da sociedade civil reforça a sugestão que seria um erro pensar que todas as interações entre as pessoas podem ser mediadas através do estreito canal de comunicação com os governos nacionais. Assim, a participação das ONGs nos debates da OMC também compensaria essa deficiência de representatividade do nível nacional.

\subsection{ARGUMENTOS CONTRÁRIOS A PARTICIPAÇÃO DAS ONGS}

As relações internacionais em sua matriz teórica realista analisam somente os Estados como agentes do sistema internacional. Esse pressuposto advém da natureza anárquica do sistema internacional, onde as relações de poder entre os Estados é fator de fundamental importância. Somente por essa perspectiva, seria inimaginável aceitar a participação das Organizações NãoGovernamentais como atores das relações internacionais. No entanto, 0 modelo teórico que utilizo aqui neste trabalho é um pouco mais flexivo, pois, do contrário, tal debate seria inconcebível de se formular.

No ponto dois, foram debatidos os modelos de governança de Shell para a OMC. Naquele ponto, optou-se pela apreciação do modelo que, 
segundo o autor, é o que melhor descreve a organização atualmente. $O$ modelo da conduta dos regimes, mais flexível que a visão realista, permite a análise da interação entre os Estados dentro de um fórum multilateral. Contudo, esse modelo mantém a apreciação dos estados como os únicos atores capazes de atuar no cenário internacional. Dessa forma, acredita-se que a presença de Organizações Não-Governamentais dentro da Organização Mundial do Comércio distorceria dramaticamente o papel dessa instituição e a desacreditaria junto aos seus membros. A seguir alguns argumentos dos principais autores que defendem a não participação das ONGs na $\mathrm{OMC}^{25}$.

O primeiro argumento e que por si só já serviria para acabar com os anseios das ONGs em participar mais efetivamente da OMC é sobre o caráter intergovernamental dessa organização. Deve-se lembrar que o nosso modelo de caracterização da governança na OMC já faz menção à essência principal das relações internacionais, quais sejam, as relações entre Estados soberanos. A promoção da participação de entidades que não estatais dentro de organismos intergovernamentais tornaria o processo decisório obscuro, e os fundamentos de sua legitimidade seriam incertos.

De acordo com essa visão, o processo de formação das políticas comerciais trabalha melhor quando os governos podem falar claramente um com o outro sem a cacofonia de outras vozes. É como Philip Nichols sugere, a participação de atores que representam uma mesma nacionalidade poderia ser confusa, pois teríamos mais de um componente doméstico se colocando nos debates internacionais, opondo, por vezes, as posições dos governos que são representantes legítimos dos Estados. Este argumento é muito bem visualizado pela metáfora das duas mordidas na maçã, pois as ONGs seriam capazes de promover um lobby em ambas as esferas nacional e internacional, levando o confronto doméstico para o seio da Organização Mundial do Comércio. E como bem disse uma vez o Embaixador da Índia na OMC: "uma organização intergovernamental como a OMC não pode funcionar efetivamente se ela lida

\footnotetext{
${ }^{25}$ Para argumentos contraries a formalização da participação das ONGs dentro da OMC, ver NICHOLS, Philip. Realism, Liberalism, Values, and the World Trade Organization. Journal of International Economic Law. Vol. 17, 1996, p.852-882 ; também SLOTBOOM, Marco. Participation of NGOs before the WTO and EC tribunals: which court is the better friend? World Trade Review, Vol.5 No. 1, 2006, p. 69-101.
}

Revista Brasileira de Direito Internacional, Curitiba, v.7, n.7, jan./jun.2008 
simultaneamente com representantes de governos e com agentes não governamentais ${ }^{26 " \text {. }}$

Outro argumento que acompanha a visão da intergovernabilidade da OMC é relativo mais a termos acadêmicos quanto à taxonomia da organização. Charnovitz alega que a participação das ONGs consiste numa base legal sólida em busca da transparência das relações que ocorrem dentro da OMC, pois o mesmo processo de legitimidade de organizações intergovernamentais por parte das ONGs já foi efetuado ${ }^{27}$. Para corrigir esse mal-entendido, Nichols utiliza-se da comparação entre modelos taxonômicos de organizações internacionais para explicar por que o exemplo de Charnovtiz foi mal elaborado.

Nichols apresenta dois tipos de categorização taxonômica das organizações internacionais. A primeira taxonomia, bem simples, mas já suficiente para desbancar o frágil argumento pró ONGs, baseia na categorização das organizações internacionais pela qualidade de seus membros. Governos soberanos sozinhos compõem o quadro de membros de uma organização intergovernamental; agências governamentais que são independentes do governo central compõem as organizações transgovernamentais; Organizações Não-Governamentais comprometem as organizações não governamentais internacionais; e, membros governos e ONGs formam uma organização híbrida. Mesmo essa simples taxonomia já é capaz de revelar as diferenças entre as organizações internacionais.

Uma taxonomia mais sofisticada explicada por Taylor ${ }^{28}$ consiste na explicação teórica das organizações internacionais. Taylor divide a explicação em três grupos: (i) teorias de regulamentação; (ii) teorias da integração; e, (iii) teorias constitucionais. Taylor analisa as seguintes variáveis para a teoria do ajustamento: coordenação, cooperação, harmonização, associação, paralelo com a ação nacional e supranacionalismo. Assim, através da visualização desses variáveis, pode-se dizer que basear os argumentos da participação das ONGs na OMC no fato de outras organizações internacionais permitirem tal

\footnotetext{
${ }^{26}$ Sem autor, Developing Countries Resist Expansion of Environmental Role for World Trade Body. International Law Environmental Review. 1999, p. 226.

${ }^{27}$ CHARNOVITZ, S. Opening, acima 12, p. 334-335.

28 TAYLOR, P. apud NICHOLS, P. Realism, acima 24, p. 858.
}

Revista Brasileira de Direito Internacional, Curitiba, v.7, n.7, jan./jun.2008 
interação depende, no mínimo, do estabelecimento de algumas similaridades entre estas e a Organização Mundial Comércio.

Terceiro, a participação da ONGs dentro dos mecanismos de formulação de políticas comercias da OMC causaria um conflito de interesses, permitindo essas competirem com os Estados. A presença de ONGs na OMC minaria a aparente autoridade dos governos, e assim, a habilidade desses governos de negociarem suas políticas estratégicas sem contestação de terceiros, respeitando a sua soberania. Os Estados ficariam constrangidos internacionalmente, visto que teriam que reformular suas estratégias de negociação, pois essas entidades poderiam comprometer o processo de barganha e os interesses como um todo da nação.

Quarto, a presença de novos membros que não Estados geraria um aumento dos gastos para organização, além, é claro, do desgaste político e da provável lentidão das tomadas de decisões. Primeiramente, para aceitar a participação das ONGs, a OMC teria que destinar uma fatia de seu escasso staff para formular critérios para escolha dessas entidades, seria necessário a formação de um órgão para avaliação constante da rigorosidade do cumprimento dos critérios pelas ONGs, além de manter um corpo permanente para avaliar a adesão de novos solicitantes. Teria que se desenvolver mecanismo que relativizassem ou que transformassem os mecanismos de votação que atualmente se baseiam no princípio do consenso, fato que seria impossibilitado ou, no mínimo, dificultado pelo fato de termos no mesmo fórum de discussões mais de um ator com a mesma nacionalidade, que poderia, por vez, discordar do governo e atrasar e encarecer a tomada de decisões.

Quinto, a manipulação permissiva da participação de grupos de interesse. Sempre que a representação de lobistas nos órgãos de tomada de decisões for permitida, haverá distorções e a promoção de influência desproporcional por parte de alguns agentes. Haveria distorções dos processos de tomada de decisões não só pela descaracterização da organização, aceitando atores não-estatais, mas principalmente pelo fato de estes lidarem com interesses especiais, sejam eles financeiros, ambientais, humanísticos, 
etc. Além disso, a ação coletiva já é passível de dificuldades quer pela votação em regime de consenso, quer pelas disparidades dos membros estatais.

Seguinte, a existência de ONGs internacionais se dá de forma mais representativa nos países desenvolvidos do que nos países em desenvolvimento. A participação das ONGs poderia, nesse caso, gerar um conflito Norte e Sul dentro da organização. Dessa forma, a maioria dos países em desenvolvimento que são membros desaprova o envolvimento das ONGs na OMC porque eles vêem grande parte das ONGs, e principalmente ONGs focadas em assuntos ambientais e laborais, como inimigos de seus interesses no seu corrente nível de desenvolvimento. Além do mais, as ONGs dos países desenvolvidos tendem a ser melhor organizadas e melhor financiadas. Há ainda o medo geral de que esta participação venha a promover um processo de marginalização dos Estados em desenvolvimento na arena de negociações. Em outras palavras, esta participação pode fazer pender o equilíbrio das negociações para os países desenvolvidos.

Outro argumento contrário a participação das ONGs é a falta de representatividade que essas possuem. Contrariando 0 argumento dos favoráveis às ONGs, o vazio de representatividade é na verdade das ONGs, pois os governos representam uma maioria da população, mesmo que não as minorias como um todo. Esta assertiva sobre a falta de reconhecimento com parcelas maiores da sociedade é bem importante, pois não conseguimos mensurar quantas e quais pessoas, em particular, estas entidades representam. Organizações Não-Governamentais com um grupo de componentes muito similares podem ainda gerar o constrangimento de pontos de vista diferentes.

Por fim, resta o debate sob a legalidade do solo já conquistado pelas ONGs dentro da Organização Mundial do Comércio. Há na matriz que defende a não-participação das ONGs na OMC, um debate sobre a interpretação errônea que permitiu a participação de amicus curiae não solicitados nos painéis de apelação e no órgão de solução de controvérsias. Primeiramente, já está definido no Artigo 1 do Dispute Settlement Understanding (DSU) que a participação em tal órgão está vedada exclusivamente aos governos dos 
Estados membros, salvo o caso do painel de apelação que permite que uma das partes envolvidas ou o painel solicite a presença de um amicus curiae. No entanto, vale ressaltar que essa figura deve ser chamada e não se autocandidatar. Esse, por conseguinte, foram os casos registrados a partir do caso do Camarão (EUA), onde o órgão apelativo permitiu a figura de amicus curiae não solicitado, contrariando o conteúdo do Artigo 13.1 da DSU que grifa a condição de busca por um amicus curiae.

Apesar de contrário a participação das ONGs ainda que nas Conferências Ministeriais, tendo em vistas não só os custos financeiros, mas também a necessidade de deslocar a atenção do pequeno staff para manter um aparato de informações disponíveis para as ONGs e outras entidades, a presente obra não enseja um retrocesso dessa etapa. Contudo, quanto os ensaios por maior espaço dentro da formação de legislações e participação efetiva nos mecanismos de solução de disputas, o argumento é preservado, pois, segundo os argumentos acima listados, não seria benéfica para a organização aceitar uma maior participação das ONGs. As perdas serão maiores que os benefícios, se estes existem.

\section{CONCLUSÃO}

As questões relativas à OMC e sua busca pelo desenvolvimento completo de seus objetivos constitutivos está no centro dos debates do sistema econômico internacional, e têm foco de discussão entre diversos grupos que ensejam participar da tomada de decisões sobre o comércio. O principal caso atualmente visualizado é o ensaio das ONGs em aumentar sua participação dentro da OMC.

Este debate, no entanto, como visualizado no correr do presente artigo, carece de uma série de fatores para resguardar tal posicionamento. Argumentos de falta de legitimidade, não representatividade do Estado, entre outros, de nada servem para comprovar a necessidade e os benefícios advindos da participação das ONGs na OMC, pois apresentam fragilidades. Além disso, o atual nível de participação das ONGs já é satisfatório per se, 
estando, em alguns casos muito além do que deveria, devendo-se promover um rearranjo, vide exemplo da participação de não solicitados amicus curiae no mecanismo de solução de controvérsias.

Por fim, validou-se a hipótese de que as ONGs não devem participar da formação de políticas comerciais em nível global. Estas entidades descaracterizariam o funcionamento e a credibilidade de uma organização intergovernamental. Dentre os principais argumentos contrários a participação das ONGs, encontramos: representação de grupos de interesse, confrontos de dois níveis com os Estados nacionais, falta de representatividade, aumento de custo para organização - tendo que formular critérios e vigiar ONGs, além de dar suporte a sua participação, etc. Dessa forma, se o objetivo da organização do comércio é melhorar o diálogo e as relações de comércio entre os países, entende-se assim, que o ideal seja a manutenção do atual quadro de membros, estendendo-se esse somente no caso da adesão de atores legítimos das relações internacionais.

\section{REFERÊNCIAS}

BROWLIE, Ian. Princípios de Direito Internacional Público. Lisboa: Oxford University Press, 1997, p.73.

CHARNOVITZ, Steve. Opening the WTO to Non-governmental Interests. Fordham International Law Journal, Vol. 24, 2000, p.191.

DUNOFF, Jeffrey. The Misguided Debate over NGO Participation at the WTO. Journal of International Economic Law, Vol. 1, No. 3, 1998, p. 433-456.

Available at SSRN: http://ssrn.com/abstract=915035

ESTY, Daniel. Non-Governmental Organizations at the World Trade Organization: Cooperation, Competition, or Exclusion. Journal of International Economic Law, Vol. 1, No. 1, 1998, p. 123-148. Available at SSRN: http://ssrn.com/abstract $=915022$

LACARTE, Julio, Transparency, Public Debate and Participation by NGOs in the WTO: A WTO Perspective. Journal of International Economic Law, Vol. 7, No. 3, 2004, p. 683-686. Available at SSRN: http://ssrn.com/abstract=917107

LIN, Zhengling. An Analysis of the Role of NGOs in the WTO

Chinese Journal of International Law, Vol.3, 2004, p. 485-497. 
MANKIW, Gregory. Principles of Macroeconomics. São Paulo: IE - WW Norton, 2006, p.11.

NICHOLS, Philip. Realism, Liberalism, Values, and the World Trade

Organization. Journal of International Economic Law. Vol. 17, 1996, p.852-882.

ORGANIZAÇÂO MUNDIAL DO COMÉRCIO. World Trade Organization.

Disponível online em http://www.wto.org. Acesso em 15.06.2009.

SANCHEZ, Michelle Ratton. Breves observações sobre os mecanismos para participação das ONGs na OMC. Sur Revista Internacional de Direitos Humanos. Vol.1, No. 4, 2006, p.103-125.

SAPRA, Seema, The WTO System of Trade Governance: The Stale NGO Debate and the Appropriate Role for Non-State Actors. Oregon Review of International Law, Vol. 11, 2009, p. 71-107. Available at SSRN:

http://ssrn.com/abstract=1403082

SHELL, Richard. Participation of nongovernmental parties in the World Trade Organization: the Trade Stakeholders Model and the participation b non-state parties in the World Trade Organization. Journal of International Economic Law. Vol. 17, 1996, p.359-371.

SLOTBOOM, Marco. Participation of NGOs before the WTO and EC tribunals: which court is the better friend? World Trade Review, Vol.5 No. 1 , 2006, p. 69101.

VAN DEN BOSSCHE, Peter, NGO Involvement in the WTO: A Comparative Perspective. Journal of International Economic Law, Vol. 11, No. 4, 2008, p. 717-749. Available at SSRN: http://ssrn.com/abstract=1305046

http://www.wto.org (acesso em 15 de junho de 2009)

Revista Brasileira de Direito Internacional, Curitiba, v.7, n.7, jan.jun.2008 